\title{
NÍVEIS DE ALCOOLEMIA E MORTALIDADE POR ACIDENTES DE TRÂNSITO NA CIDADE DO RIO DE J ANEIRO
}

\author{
Alcoholemy Levels and Mortality by Traffic \\ Accidents in the City of Rio de J aneiro \\ Niveles de Al coholemia y Mortalidad por Accidentes de \\ Tránsito en la Ciudad de Rio de J aneiro
}

\section{Resumo}

Trata-se de estudo epidemiológico descritivo. Objetivou descrever o perfil das vítimas fatais por acidentes de trânsito na cidade do Rio de Janeiro a partir dos registros do Instituto Medico Legal e compará-los aos níveis de alcoolemia detectados através do exame laboratorial. A coleta de dados obedeceu à Resolução 196/96 do Conselho Nacional de Saúde. Os dados foram levantados no arquivo do IML, através dos registros nos prontuários de vítimas fatais por acidentes de trânsito, do universo das vítimas por todas as causas externas, e registrados a partir de um sistema de informação específico, compilados e tabulados pelo programa estatístico EPI INF0, no período compreendido entre janeiro e fevereiro de 2005 . Evidenciou-se que $27,8 \%$ das vítimas fatais apresentaram alcoolemia detectada. Em $64 \%$ desses, o nível de alcoolemia foi acima de 0,6 g/L, enquanto $36 \%$ apresentaram um percentual significativo de mortalidade com níveis abaixo do limite legal estabelecido no Brasil.

Palavras-chave: Etanol. Acidentes de Trânsito. Mortalidade.

\begin{abstract}
This is an epidemiologic descriptive study. With the objective to describe the profile of the fatal victims by traffic accidents in the city of Rio de Janeiro from the records of the MedicalLegal Institute and to compare it to the levels of alcoholemy detected trough laboratorial examination. The data collection was made according to the Resolution 196/96 of the National Council of Health. The data was raised in archives of the MLI, trough the medical records of the fatal victims of traffic accidents, of the victims' universe by all the external causes, and recorded from a specific information system, grouped and tabulated by the statistic program EPI INFO, in the period between January and February of 2005. It became evident that $27.8 \%$ of the fatal victims presented detected alcoholemy. In $64 \%$ of these, the alcoholemy level was above $0.6 \mathrm{~g} / \mathrm{L}$, while $36 \%$ presented a significant perceptual of mortality with levels below the legal limit established in Brazil.
\end{abstract}

\section{Resumen}

Se trata de un estudio epidemiológico descriptivo. Con el objetivo de describir el perfil de las víctimas fatales de tránsito en la ciudad de Rio de Janeiro desde los registros del Instituto Medico Legal (IML) y compárarlos a los niveles de alcoholemia detectados a través del examen en laboratorio. La colecta de los datos obedeció a la Resolución 196/96 del Consejo Nacional de Salud. Los datos fueran levantados en el archivo del IML, a través de los registros en los prontuarios de víctimas fatales por accidentes de tránsito, del universo de las víctimas por todas las causas externas, y registrados desde un sistema de información específico, compilados y tabulados por el programa estadístico EPI INFO, en el período comprendido entre enero y febrero de 2005 . Fue evidenciado que $27,8 \%$ de la víctimas fatales presentaran alcoholemia detectada. En $64 \%$ de esos, el nivel de alcoholemia fue arriba de 0,6g/L, mientras $36 \%$ presentaran un porcentual significativo de mortalidad con niveles abajo del limite legal establecido en el Brasil.
Keywords:

Ethanol. Accidents, Traffic. Mortality.
Palabras clave:

Etanol. Accidentes de Tránsito. Mortalidad. 


\section{INTRODUÇÃO}

Nos dias atuais, a violência urbana é uma grande preocupação para a Saúde Pública. Os acidentes de trânsito, com vítimas fatais ou não fatais com seqüelas, contribuem para o aumento da taxa de morbimortalidade de modo expressivo, sendo considerados uma verdadeira epidemia face à sua extensão e às conseqüências para o indivíduo, a família e a sociedade, além dos prejuízos econômicos ${ }^{1}$.

Segundo relatório da Organização Mundial de Saúde - OMS, os acidentes de trânsito matam 1,2 milhão de pessoas a cada ano e representam 2,3\% do número total de mortes, tratando-se, portanto, de uma das principais causas de morte no mundo 2 .

Projeções para o ano de 2020 apontam que os acidentes de trânsito ocuparão $03^{\circ}$ lugar nas causas gerais de mortalidade mundial ${ }^{2}$. No entanto, essa projeção só se concretizará se os países de média e baixa renda não adotarem medidas necessárias a respeito e, sobretudo, se seguirem considerando que as lesões e mortes por veículos não são preveníveis, desconhecendo os fatores geradores de sua ocorrência ${ }^{3}$.

No Brasil, as estatísticas apresentadas pelo Departamento Nacional de Trânsito, do Ministério dos Transportes, demonstram que, no ano de 2000, ocorreram 324.222 acidentes com vítimas, dos quais resultaram 22.102 mortes e 408.070 feridos, não havendo registro do número de ocorrências que redundaram apenas em danos materiais ${ }^{4}$.

0 consumo de bebidas alcoólicas pode ser apontado como um dos principais fatores responsáveis pela alta incidência dos acidentes com vítimas. De maneira geral, em vários países costumase considerar que entre metade e um quarto dos acidentes com vítimas fatais estão associados ao uso do álcool 5,6 .

Em nosso país, o consumo de bebidas alcoólicas também é apontado como um dos principais fatores causais de acidentes. Em aproximadamente $70 \%$ dos acidentes violentos com mortes no trânsito, 0 álcool é o principal responsável ${ }^{7}$.

Apesar das estatísticas elevadas, ainda não se tem um estudo conclusivo de qual deveria ser o limite máximo de ingestão alcoólica seguro para a direção de veículos automotores. Nas legislações dos diferentes países, que possuem leis referentes à direção e álcool, verificamos que a taxa de alcoolemia varia de 0,2 $\mathrm{g} / \mathrm{L}$ até $1,0 \mathrm{~g} / \mathrm{L}$. No Brasil foi instituído em 1997 o Código de Trânsito Brasileiro - CTB (lei $n^{0}$ 9.503), que estipula, em seu artigo 276, que o limite permitido de alcoolemia para que o condutor se ache seguro para a direção é de até 0,6 gramas de álcool por litro de sangue ${ }^{8}$.

Dessa forma, é importante observar que qualquer bebida alcoólica contém a mesma quantidade de álcool puro por dosepadrão e que, sob este ângulo, não existe "bebida fraca". Ao bebermos um copo de $300 \mathrm{~mL}$ de cerveja, estaremos ingerindo a mesma quantidade de álcool puro ( $12 \mathrm{~g})$ e alcançando $0,2 \mathrm{~g} /$ $L$ de sangue (alcoolemia). Então, de modo geral, podemos dizer que 3 copos de cerveja seriam suficientes para atingir a alcoolemia máxima permitida. Nessa concentração de 0,6 g/L, o álcool já provoca no cérebro alterações neuroquímicas e funcionais suficientes para mudanças de comportamento facilitadores da violência e outras conseqüências ${ }^{\text {? }}$.

Segundo pesquisa realizada na cidade do Rio de Janeiro sobre a mortalidade nos acidentes de trânsito relacionados à alcoolemia, das 181 vítimas de acidentes de trânsito que foram submetidas ao exame da alcoolemia, $42,5 \%$ apresentaram índices de alcoolemia detectada. Desses, 22,3\% apresentaram resultados entre 0,1 e $0,39 \mathrm{~g} / \mathrm{L}$ de sangue no organismo ${ }^{1} .0$ que pode nos levar a pensar a respeito do limite legal de alcoolemia, já que existem vítimas de acidentes de trânsito que apresentam concentrações de álcool no sangue inferiores às permitidas pela legislação vigente.

Diante dos dados apresentados, e ainda levando em consideração a insuficiência de medidas preventivas e a necessidade de uma ação pronta e combinada para as questões referentes ao uso/abuso de álcool no trânsito, esse flagelo de nossos tempos, os estudos e as pesquisas sobre o tema são de notória importância, principalmente se levarmos em consideração que as estatísticas disponíveis em nosso país ainda são insuficientes, não demonstrando a real face da situação ${ }^{6}$.

Dessa forma, o estudo teve como objetivos: descrever o perfil das vítimas fatais por acidentes de trânsito na cidade do Rio de Janeiro - RJ, a partir dos registros do Instituto Medico Legal, e compará-lo aos níveis de alcoolemia detectados através do exame laboratorial.

\section{METODOLOGIA}

0 estudo foi epidemiológico descritivo, realizado no Instituto Médico Legal Afrânio Peixoto (IML-AP), para onde são encaminhadas todas as vítimas fatais envolvidas em causas violentas na cidade do Rio de Janeiro e adjacências.

Os dados foram levantados dos prontuários de vítimas fatais por acidentes de trânsito (colisão, atropelamento, choque, queda de moto, outros), do universo das vítimas por todas as causas externas, e registrados a partir de um sistema de informação específico do IML, numa planilha no setor do arquivo, no período compreendido entre janeiro e fevereiro de 2005. Desses prontuários analisados, foram identificadas 214 vítimas de causas externas nos dois primeiros meses de 2005, das quais $90(42,1 \%)$ decorrentes de acidentes de trânsito.

As variáveis estudadas estavam relacionadas às características sócio-demográficas das vítimas, como: sexo, faixa etária, estado civil, escolaridade, cor/raça e naturalidade, e às características dos acidentes, como: turno (dividido em manhã: $6 \mathrm{~h}$ às $11 \mathrm{~h} 59 \mathrm{~m}$; tarde: $12 \mathrm{~h}$ às $17 \mathrm{~h} 59 \mathrm{~m}$; noite: $18 \mathrm{~h}$ às $23 \mathrm{~h} 59 \mathrm{~m}$; madrugada: $0 \mathrm{~h}$ às $5 \mathrm{~h} 59 \mathrm{~m}$ ), dia da semana, local do acidente (dividido por Áreas de Planejamento da Secretaria Municipal de Saúde do Rio de Janeiro), tipo de acidente e realização do exame de alcoolemia.

As análises foram feitas a partir dos dados coletados, compilados e tabulados pelo programa estatístico EPI INFO, que utiliza a análise estatística simples da freqüência das variáveis sócio-demográficas, características dos acidentes e níveis de alcoolemia, apresentadas sob forma de tabelas. 
0 referido estudo faz parte de uma linha de pesquisa, de um estudo piloto, sobre Trânsito e Álcool da Escola de Enfermagem Anna Nery/UFRJ, que foi submetido aos procedimentos normativos do Comitê de Ética e Pesquisa (CEP) do Instituto Médico Legal Afrânio Peixoto em novembro de 2005. E, em setembro de 2006, através de uma carta de autorização para continuidade do estudo, emitida pelo diretor do CEP do IML, iniciou-se o atual estudo.

\section{APRESENTAÇÃO DOS RESULTADOS E DISCUSSÃO}

\section{Tabela 1:}

Distribuição das Características Sócio-Demográficas das Vítimas Fatais de Acidentes de Trânsito no Município do Rio de Janeiro nos Meses de Janeiro e Fevereiro de 2005 ( $n=90)$.

\begin{tabular}{|c|c|c|}
\hline \multirow{2}{*}{$\begin{array}{c}\text { Características } \\
\text { Sexo }\end{array}$} & \multicolumn{2}{|c|}{ Sócio-Demográficas } \\
\hline & $\mathrm{N}$ & $\%$ \\
\hline Masculino & 73 & 81,1 \\
\hline Feminino & 17 & 18,9 \\
\hline Faixa Etária (em anos) & $\mathrm{N}$ & $\%$ \\
\hline $1 \mid-14$ & 5 & 5,6 \\
\hline $14 \mid-26$ & 10 & 11,1 \\
\hline $26 \mid-40$ & 24 & 26,7 \\
\hline $40 \mid-60$ & 31 & 34,4 \\
\hline $60 \mid$ e mais & 17 & 18,9 \\
\hline Ignorado & 3 & 3,3 \\
\hline Estado civil & $\mathrm{N}$ & $\%$ \\
\hline Solteiro & 43 & 47,7 \\
\hline Casado & 27 & 30 \\
\hline Viúvo & 10 & 11,1 \\
\hline Divorciado & 5 & 5,6 \\
\hline Ignorado & 5 & 5,6 \\
\hline Escolaridade & $\mathrm{N}$ & $\%$ \\
\hline Analfabetos & 6 & 6,7 \\
\hline Ensino Fundamental Incompleto & 14 & 15,6 \\
\hline Ensino Fundamental Completo & 32 & 35,5 \\
\hline Ensino Médio Completo & 18 & 20 \\
\hline Ensino Superior Completo & 8 & 8,9 \\
\hline Ignorado & 12 & 13,3 \\
\hline Cor/Raça & $\mathrm{N}$ & $\%$ \\
\hline Branco & 38 & 42,2 \\
\hline Negro & 7 & 7,8 \\
\hline Mulato/Mestiço & 45 & 50 \\
\hline Naturalidade & $\mathrm{N}$ & $\%$ \\
\hline Rio de Janeiro & 61 & 67,8 \\
\hline Outros Estados & 16 & 17,8 \\
\hline Outros Países & 3 & 3,3 \\
\hline Ignorado & 10 & 11,1 \\
\hline
\end{tabular}

No levantamento realizado para este estudo verificamos que a maioria das vítimas fatais foi do sexo masculino $(81,1 \%)$ na faixa etária entre 26 e 60 anos de idade $(61,1 \%)$, porém se concentrando na faixa etária de 40 a 60 anos de idade, com um total de 31 vítimas $(34,4 \%)$.

Quanto ao sexo, podemos verificar que existe uma predominância de óbitos de pessoas do sexo masculino também observada em outros estudos ${ }^{1,5,6,9,10}$, fazendo desta uma característica dos acidentes de trânsito com vítimas fatais.

Os homens geralmente fazem uso do álcool em maior número de vezes e em maior quantidade do que as mulheres. Isto caracteriza a maior exposição do homem ao álcool; conseqüentemente, eles apresentam comportamentos sociais e culturais que o predispõem, em maiores proporções, aos riscos de lesões e mortes. ${ }^{1,11}$

Estudos correlatos encontraram características relacionadas à faixa etária próximas a esta pesquisa. Este fato evidencia o grande número de pessoas em idade produtiva e participativa do mercado de trabalho que são retiradas deste contexto. ${ }^{1,5,6}$

Dessa forma, podemos dizer que os adultos jovens estão mais próximos dos acidentes e da violência, pois a maior busca de emoções, o prazer em experimentar sensações de

Tabela 2:

Distribuição das Mortes no Trânsito, segundo as Características dos Acidentes de Trânsito no Município do Rio de Janeiro no Período de Janeiro e Fevereiro de 2005 ( $n=90$ ).

\begin{tabular}{|c|c|c|}
\hline \multicolumn{3}{|c|}{ Características dos Acidentes } \\
\hline Turno & $\mathrm{N}$ & $\%$ \\
\hline Manhã & 20 & 22,2 \\
\hline Tarde & 17 & 18,9 \\
\hline Noite & 28 & 31,1 \\
\hline Madrugada & 20 & 22,2 \\
\hline Ignorado & 5 & 5,6 \\
\hline Dias da Semana & $\mathrm{N}$ & $\%$ \\
\hline Segunda-feira & 6 & 6,7 \\
\hline Terça-feira & 6 & 6,7 \\
\hline Quarta-feira & 13 & 14,4 \\
\hline Quinta-feira & 10 & 11,1 \\
\hline Sexta-feira & 19 & 21,1 \\
\hline Sábado & 23 & 25,6 \\
\hline Domingo & 13 & 14,4 \\
\hline Local do Óbito & $\mathbf{N}$ & $\%$ \\
\hline Via Pública & 42 & 46,7 \\
\hline Hospital & 48 & 53,3 \\
\hline Tipo de Acidente & $\mathrm{N}$ & $\%$ \\
\hline Atropelamento & 47 & 52,2 \\
\hline Colisão* & 21 & 23,3 \\
\hline Choque $^{* *}$ & 7 & 7,8 \\
\hline Queda de Moto & 6 & 6,7 \\
\hline Ignorado & 9 & 10 \\
\hline Local do Acidente por AP** & $\mathrm{N}$ & $\%$ \\
\hline AP 1.0 & 11 & 12,2 \\
\hline AP 2.1 & 7 & 7,8 \\
\hline AP 2.2 & 7 & 7,8 \\
\hline AP 3.1 & 18 & 20 \\
\hline AP 3.2 & 8 & 8,9 \\
\hline AP 3.3 & 11 & 12,2 \\
\hline AP 4.0 & 10 & 11,1 \\
\hline AP 5.1 & 3 & 3,3 \\
\hline AP 5.2 & 8 & 8,9 \\
\hline AP 5.3 & 3 & 3,3 \\
\hline Baixada Fluminense & 2 & 2,2 \\
\hline Outras Localidades & 2 & 2,2 \\
\hline
\end{tabular}

* Acidente com impacto entre veículos em movimento (BRASIL, 2002)

** Impacto de um veículo em movimento contra qualquer objeto fixo (op.cit., 2002) *** Área de Planejamento 
risco e, principalmente, o uso e abuso de álcool e outras drogas são termos associados ao comportamento de jovens e adultos jovens que podem contribuir para a maior incidência de acidentes de trânsito nessa faixa etária.

Vale a pena ressaltar o percentual de pessoas idosas na faixa de 60 anos e mais vítimas de acidentes de trânsito. Outros estudos também corroboram este resultado ${ }^{1,11}$. 0 risco de mortes por acidentes de trânsito é maior na população idosa, principalmente nos países em desenvolvimento; os idosos estão mais expostos a atropelamentos, enquanto os adultos jovens apresentam maior risco para colisão entre veículos a motor ${ }^{3,12}$.

Ao analisarmos a Tabela 2, na página anterior, podemos verificar que o turno em que ocorreu o maior número de óbitos por acidentes de trânsito foi o período da noite, perfazendo um total de $31,1 \%$, seguido do turno da madrugada e do turno da manhã, com 22,2\% dos óbitos em cada turno.

0 acúmulo de óbitos no período da noite sugere que esta ocorrência se deva ao cansaço, que é maior no final do dia, e também ao elevado número de veículos neste horário, circulando pela cidade. Aliado a estes fatos, podemos citar também que, no período noturno e da madrugada, ocorrem o desrespeito aos semáforos, excesso de velocidade, dificuldade de atendimento imediato das vítimas de acidentes de trânsito, entre outros fatores. Já no período da manhã, temos um grande número de pessoas nas ruas se deslocando para o trabalho, repetindo o quadro do turno da noite no que se refere ao aumento de veículos nas vias públicas.

Percebe-se um grande número das vítimas no final de semana, iniciando na sexta-feira, sendo o sábado o dia da semana em que verificamos a maior concentração de vítimas nos acidentes de trânsito.

Nesse sentido, existe uma corroboração entre os estudos $^{1,2,3,5,6,12}$ que relacionam ingestão de álcool e acidentes de trânsito ao número elevado de acidentes que ocorrem principalmente nos finais de semana. É neste período que as pessoas costumam fazer uso com mais freqüência de bebidas alcoólicas e ou drogas.

Podemos ainda observar neste estudo que a maior freqüência em relação ao tipo de acidente foi para o atropelamento, seguido dos acidentes causados por colisão.

Os pedestres, por sofrerem o impacto direto em caso de atropelamentos, são as vítimas com maior probabilidade de serem internadas e morrerem após terem sofrido um acidente, se configurando no grupo mais vulnerável aos acidentes de trânsito em relação aos motoristas e passageiros.

Os acidentes de trânsito incluem predominantemente os atropelamentos e as colisões, segundo estudo que trata do impacto do álcool na mortalidade em acidentes de trânsito ${ }^{6}$. Ainda neste estudo, somente $1 / 3$ das vítimas fatais nos acidentes de trânsito estavam embarcadas nos veículos; portanto, cerca de 2/3 ocorreu por atropelamentos.

Esses eventos chamam a atenção não só por ocorrerem em número elevado, mas também por atingirem uma população de idosos e crianças. Nesse caso, são os pedestres os mais prejudicados, o que parece confirmar o relatório do Instituto de Pesquisa Econômica e Aplicada (IPEA) ${ }^{13}$ sobre mortalidade no trânsito, quando afirma, serem os pedestres as maiores vítimas de acidentes de trânsito no Brasil. Esse resultado sinaliza um país em desenvolvimento ainda com poucas ações e estratégias efetivas no sentido do enfrentamento da prevenção, junto aos órgãos governamentais, em relação a essa problemática.

Dessa forma, podemos verificar, no estudo, que a região da cidade do Rio de Janeiro onde ocorreu o maior número de mortes na AP 3.1 (Área de Planejamento que abrange em torno de treze bairros da zona norte da cidade, incluindo a llha do Governador) é uma região com muito movimento de tráfego, pois grande parte desses bairros é atravessada pela Avenida Brasil, por onde trafegam uma grande quantidade de veículos de pequeno, médio e grande porte em qualquer turno do dia, em alta velocidade. Alguns locais se apresentam sem pavimentação, iluminação, sinalização, passarelas e passagens para pedestres para fazer sua travessia de um lado para 0 outro com segurança e tranqüilidade. Ainda nesses bairros encontramos avenidas principais nas mesmas condições.

Dados do DETRAN-RJ apontam que no ano de 2004 a Avenida Brasil foi a campeã de ocorrências de acidentes de trânsito, com 100 mortes no ano. Destas, 92\% foram provocadas por falhas humanas, das quais $35 \%$ ocorreram por abuso de bebida alcoólica ${ }^{1}$.

Dessa forma, sabe-se que uma urbanização sem preocupações com a qualidade de vida e a humanização leva à disputa de pessoas e veículos pelo mesmo espaço, vencendo o mais forte: o veículo e o ser humano motorizado. Prejudicados e vitimados ficam os pedestres, que compõem o grupo populacional dos trabalhadores que, às vezes, são de poder aquisitivo mais baixo, freqüentemente já discriminados pelas próprias condições de vida ${ }^{12}$.

\section{Tabela 3:}

Distribuição das Mortes no Trânsito, segundo a Realização do Exame de Alcoolemia no Município do Rio de Janeiro, nos Meses de Janeiro e Fevereiro/2005 ( $n=90)$.

\begin{tabular}{lccc}
\hline Resultado do Exame de & Alcoolemia* & N & \% \\
\hline Não Realizado & 58 & 64,4 \\
Detectado & 25 & 27,8 \\
Não Detectado & 7 & 7,8 \\
\hline
\end{tabular}

*Utilizando-se a técnica de Cromatografia Gasosa ( $\geq 0,1 \mathrm{~g} / \mathrm{L})$

Na Tabela 3 podemos evidenciar que, na maioria dos casos de acidentes no trânsito com vítimas fatais atendidas pelo IML, não foi realizado o exame para detecção da alcoolemia $(64,4 \%)$. Do restante, $27,8 \%$ das vítimas apresentavam alcoolemia detectada pelo método de cromatografia gasosa.

Este baixo número de verificação da alcoolemia nas vítimas é decorrente da rotina do IML, que prioriza a realização desse exame nas vítimas oriundas da via pública. Nos casos de óbito hospitalar, só é realizado o exame se a vítima chegar ao IML dentro das primeiras 12 horas após a morte ou se o médico que fez 0 atendimento hospitalar assim o solicitar.

Podemos perceber que, mesmo não se verificando a taxa de alcoolemia, por motivos diversos que a limitação desse estudo não nos permitiu avaliar, em todas as vítimas de acidentes de trânsito, temos um quantitativo considerável de vítimas que 
apresentaram a alcoolemia detectável $(27,8 \%)$, o que evidenciou o envolvimento do álcool com os acidentes de trânsito.

Dessa forma, outros estudos realizados na cidade do Rio de Janeiro evidenciaram resultados semelhantes, o que nos leva a perceber que, se a legislação brasileira efetivamente obrigasse a verificação da alcoolemia e dosagem de outras drogas em todas as vítimas de acidentes de trânsito, fatais ou não, haveria condições de estabelecer uma análise mais completa dessa situação ${ }^{1,6}$.

Tabela 4:

Distribuição das Mortes no Trânsito, segundo a Alcoolemia Detectada no Município do Rio de Janeiro, nos Meses de Janeiro e Fevereiro/2005 ( $n=25)$.

\begin{tabular}{llll}
\hline Alcoolemia Detectada em & $\mathbf{g} / \mathrm{L}$ & $\mathbf{N}$ & $\%$ \\
\hline Acima de $0,6 \mathrm{~g} / \mathrm{L}$ & 16 & 64 \\
Abaixo de $0,6 \mathrm{~g} / \mathrm{L}$ & 09 & 36 \\
\hline
\end{tabular}

A Tabela 4 mostra que, das 25 vítimas fatais de acidentes no trânsito com alcoolemia detectada, $64 \%$ apresentaram níveis de alcoolemia acima do permitido de acordo com o Código de Trânsito Brasileiro, ou seja, acima de 0,6g/L. Porém percebemos também a existência de um quantitativo expressivo de óbitos com alcoolemia abaixo de 0,6g/L, o que nos mostra que indivíduos estão morrendo por acidentes de trânsito envolvidos com álcool mesmo abaixo do limite de tolerância, sinalizando uma preocupação nesse sentido.

Dados semelhantes também foram encontrados em estudo realizado na cidade do Rio de Janeiro, onde $37,7 \%$ das vítimas fatais por acidentes de trânsito apresentavam alcoolemia entre $0,1 \mathrm{~g} / \mathrm{L}$ e $0,5 \mathrm{~g} / \mathrm{L}^{1}$. Os autores afirmam, ainda, que estes dados fortalecem a importância de se considerarem os níveis de alcoolemia inferiores ao estabelecido pelo CTB $(<0,6 \mathrm{~g})$ $\mathrm{L})$, pois o quantitativo de óbitos averiguados tem demonstrado significância do ponto de vista da tolerância do álcool no organismo, estabelecido em nosso país, para dirigir qualquer veículo motor.

A alcoolemia em torno de 0,2 a 0,6 g/L já pode representar efetivo fator de risco ao provocar manifestações neurocognitivas e comportamentais, e, ainda nessa faixa, o álcool pode promover euforia, desinibição, impulsividade, agressividade ou passividade ${ }^{7}$. Tais considerações são importantes no que tange a possibilidades de riscos com níveis mais baixos do que é habitualmente permitido.

Nos eventos violentos, em que o álcool atua como facilitador ou desencadeador efetivo (acidentes de tráfego, agressões ou brigas, homicídios, acidentes domésticos e de trabalho...), a alcoolemia não precisa ser tão alta, uma vez que, levando-se em conta características de personalidade e de cultura, a supressão da ação inibidora do lobo frontal provocada pelo álcool pode ocorrer com doses menores ${ }^{7}$.

Chamamos, então, a atenção para os acidentes automotivos nos quais se detectam níveis alcoólicos inferiores à taxa permitida pela legislação brasileira, isto é abaixo de $0,6 \mathrm{~g} / \mathrm{L}$ de sangue. Não podemos descartar estes dados, abaixo do limite de tolerância, mais sim devemos estar atentos para este fato, uma vez que o consumo de bebidas alcoólicas, ligado aos acidentes de trânsito, aumenta nos países em desenvolvimento, principalmente entre os jovens ${ }^{3}$.

Tabela 5:

Distribuição do Perfil das Vítimas Fatais e das Características dos Acidentes de Trânsito, segundo a Alcoolemia Detectada no Município do Rio de Janeiro, nos Meses de Janeiro e Fevereiro /2005 ( $n=25)$.

\begin{tabular}{|c|c|c|c|c|c|c|}
\hline \multirow{2}{*}{$\frac{\text { Variáveis }}{\text { Sexo }}$} & \multicolumn{2}{|c|}{ Total } & \multicolumn{2}{|c|}{$\begin{array}{c}\text { Alcoolemia } \\
\geq 0,6 \mathrm{~g} / \mathrm{L}\end{array}$} & \multicolumn{2}{|c|}{$\begin{array}{l}\text { Detectada } \\
<0,6 \mathrm{~g} / \mathrm{L}\end{array}$} \\
\hline & $\mathrm{N}$ & $\%$ & N & $\%$ & $N$ & $\%$ \\
\hline Masculino & 22 & 88 & 16 & 64 & 6 & 24 \\
\hline Feminino & 3 & 22 & - & - & 3 & 22 \\
\hline Faixa Etária & $\mathrm{N}$ & $\%$ & $\mathrm{~N}$ & $\%$ & $\mathrm{~N}$ & $\%$ \\
\hline $14 \mid-26$ & 4 & 16 & 2 & 8 & 2 & 8 \\
\hline $26 \mid-40$ & 6 & 24 & 4 & 16 & 2 & 8 \\
\hline $40 \mid-60$ & 10 & 40 & 7 & 28 & 3 & 22 \\
\hline $60 \mid$ e mais & 4 & 16 & 2 & 8 & 2 & 8 \\
\hline Ignorado & 1 & 4 & 1 & 4 & - & - \\
\hline Dia da Semana & N & $\%$ & $\mathrm{~N}$ & $\%$ & $\mathrm{~N}$ & $\%$ \\
\hline Segunda-feira & 3 & 12 & 3 & 12 & - & - \\
\hline Terça-feira & - & 一 & - & - & - & - \\
\hline Quarta-feira & 3 & 12 & 1 & 4 & 2 & 8 \\
\hline Quinta-feira & 2 & 8 & 2 & 8 & - & - \\
\hline Sexta-feira & 3 & 12 & 2 & 8 & 1 & 4 \\
\hline Sábado & 9 & 36 & 7 & 28 & 2 & 8 \\
\hline Domingo & 5 & 20 & 2 & 8 & 3 & 12 \\
\hline Local do Óbito & $\mathrm{N}$ & $\%$ & $\mathrm{~N}$ & $\%$ & $\mathrm{~N}$ & $\%$ \\
\hline Via Pública & 17 & 68 & 13 & 52 & 4 & 16 \\
\hline Hospital & 8 & 32 & 4 & 16 & 4 & 16 \\
\hline Tipo de Acidente & $\mathrm{N}$ & $\%$ & $\mathrm{~N}$ & $\%$ & $\mathrm{~N}$ & $\%$ \\
\hline Atropelamento & 11 & 44 & 7 & 28 & 4 & 16 \\
\hline Colisão & 8 & 32 & 6 & 24 & 2 & 8 \\
\hline Choque & 5 & 20 & 4 & 16 & 1 & 4 \\
\hline Queda de Moto & 1 & 4 & - & - & 1 & 4 \\
\hline
\end{tabular}

Ao correlacionarmos os dados da Tabela 5, podemos verificar, no que se refere à sobremortalidade dos homens, que esta é bem maior do que a das vítimas do sexo feminino, e que os níveis de alcoolemia das vítimas masculinas em $64 \%$ dos óbitos mostravam-se superiores ao limite legal de 0,6g/L. Esse dado pode ser explicado pelo comportamento do gênero masculino, que, diferentemente do feminino, adota determinadas atitudes como: dirigir em maior velocidade, maior consumo de álcool, maior agressividade, tendência a realizar manobras arriscadas, entre outros ${ }^{10}$.

Quanto à faixa etária, verificamos uma maior freqüência de níveis alcoólicos acima de 0,6g/L nas vítimas entre 40 e 60 anos de idade. Quanto à freqüência nos níveis abaixo de $0,6 \mathrm{~g} /$ $L$, também encontramos uma maior concentração nessa mesma faixa etária, o que nos mostra que, mesmo com a limitação do estudo, a faixa etária que mais abusou do álcool em todos os níveis não foi a dos jovens e adolescentes, e sim a dos adultos.

Ao verificarmos os dias da semana nos quais ocorreram os óbitos, $28 \%$ das vítimas com alcoolemia maior que $0,6 \mathrm{~g} / \mathrm{L}$ morreram no sábado, o que mostra o abuso maior do álcool nos fins de semana. Chamam-nos a atenção os $12 \%$ das vítimas 
que faleceram no domingo apresentando alcoolemia abaixo de $0,6 \mathrm{~g} / \mathrm{L}$. Por inferência, podemos acreditar que estes dados revelam o hábito de consumo de bebidas alcoólicas em menor intensidade no domingo, porém favorecendo acidentes que levam à morte.

Quanto ao local do óbito, $52 \%$ das vítimas oriundas das vias públicas apresentaram níveis acima de 0,6 gramas de álcool por litro de sangue, dessa forma apontando que, quanto maior a gravidade do acidente, maior o envolvimento do álcool, determinando a magnitude do problema abordado em relação ao uso abusivo de bebidas alcoólicas e direção.

Percebemos também que os níveis de alcoolemia abaixo do permitido legalmente também levou a óbito um percentual de indivíduos que foram socorridos em via pública e chegou até ao hospital, o que nos mostrou que mesmo abaixo do limite de tolerância esses indivíduos vieram a óbito.

No que se refere ao tipo de acidente, $28 \%$ das vítimas de atropelamento apresentaram alcoolemia acima do permitido, e $24 \%$ que sofreram colisão também apresentaram alcoolemia acima do permitido legalmente. Esses dados nos mostra a gravidade do envolvimento do uso do álcool nos acidentes de trânsito, sobretudo se também levarmos em consideração o quantitativo de vítimas fatais com níveis de alcoolemia abaixo de 0,6 g/L.

\section{CONCLUSÃO}

Embora o presente estudo tenha apresentado limitações em relação ao período de tempo pesquisado e ao quantitativo de exames realizados pelo IML no período, os dados evidenciaram alguns resultados importantes, tais como: $27,8 \%$ das vítimas fatais apresentaram alcoolemia detectada. Em $36 \%$ desses, o nível de alcoolemia foi abaixo de $0,6 \mathrm{~g} / \mathrm{L}$, o que demonstra a necessidade de maior atenção para esses níveis, por que sabemos, e a literatura aponta, que, bem antes desse índice, 0 álcool começa a afetar as funções cognitivas de quem dirige ${ }^{7}$.

E ainda, ao correlacionar a alcoolemia detectada com as variáveis do perfil sócio-demográfico e das características dos acidentes, observaram-se números significativos de vítimas com alcoolemia abaixo de $0,6 \mathrm{~g} / \mathrm{L}$.

Ainda podemos ressaltar neste contexto um fator importante e que de certa forma limitou o estudo, foi a falta de informação, melhor dizendo, a subnotificação encontrada nos registros dos acidentes automobilísticos. Autores ${ }^{1,9}$ referem a preocupação com a subnotificação ou o mau preenchimento dos registros de ocorrências, no sentido de melhor traçar definições de políticas públicas para determinados fins

Percebemos, então, que se deve trabalhar arduamente nas formas de prevenção dos acidentes e que a legislação em vigor deve ser revista no sentido da sua efetividade, com maior presença efetiva dos policiais, fazendo a ronda pela cidade, utilizando bafômetros nas ruas, principalmente nos fins de semana, em locais onde a concentração de pessoas em bares e boates é maior, o que faz com que o consumo de bebidas alcoólicas aumente em todas as faixas etárias. Dessa forma, haverá a possibilidade de ação ampla entre os jovens, passando pelos adultos e chegando até os idosos.

\section{Referências}

1. Abreu AMM. Mortalidade nos acidentes de transito na cidade do Rio de Janeiro relacionada ao uso e abuso de bebidas alcoólicas [tese de doutorado]. Rio de Janeiro (RJ): Escola de Enfermagem Anna Nery/UFRJ; 2006.

2. Organização Mundial de Saúde - OMS. Os acidentes de trânsito matam 1,2 milhão de pessoas a cada ano. [on line] 2002. [citado 25 out 2006]; [aprox. 2 telas]. Disponivel em http://www.abramet.org/monografia/ default.asp?id $=125 \& 0 Q=$ monografia $\& 0 Q 2=$ monografia\&OQ3 $=$.

3. Informe mundial sobre prevención de los traumatismos causados por el transito. Resumen. Ginebra,2004.

4. Ministério dos Transportes (BR). Programa Pare-procedimentos para o tratamento de locais críticos de acidentes de trânsito. Brasilia (DF); jul 2002.

5. Scalassara MB; Souza RKT, Soares DFPP. Características da mortalidade por acidentes de trânsito em localidades da região Sul do Brasil. Rev Saude Publica, 1998 abr; 32 (2): 125-32.

6. Abreu AMM, Lima JMB, Alves TA. 0 impacto do álcool na mortalidade dos acidentes de trânsito: uma questão de saúde pública.Esc Anna Nery Rev Enferm; 2006 abr; 10(1)

7. Lima JMB. Alcoologia: uma visão sistêmica dos problemas relacionados ao uso e abuso do álcool. Rio de Janeiro (RJ): UFRJ/EEAN; 2003.
8. Lei no 9.503 de 23 de setembro de 1997. Institui o Código de Trânsito Brasileiro. [on line] [citado 18 out 2006]; [aprox. 125 telas]. Disponível em: http://www.senado.gov.br/web/codigos/transito/httoc.htm.

9. Mourão LNG, Muñoz DR, Mourão TTG, Andrade AG. A embriaguez e o trânsito: avaliação da nova lei de trânsito no que se refere à abordagem da embriaguez. Rev Psiquiatr Clin -Ed Esp Álcool e Drogas p 2 [periódico on line] 2000 mar/abr; [citado 29 maio 2006]; 27 (2): [aprox. 10 telas]. Disponível em: http://www.hcnet.usp.br/ipq/revista/r27(2)/art83.htm.

10. Mello MHP, Laurenti R. Acidentes e violência no Brasil. Rev Saude Publica 1997 ago; 31 (4 supl): 51-54.

11. Malaquias JV, Reis AC, Souza ER, Minayo MCS. Mortalidade por acidentes de transportes no Brasil - 1999. Bol Centro Latino-Americano de Estudos de Violência e Saúde Jorge Careli - CLAVES [periódico on line] 2002 jul; [citado 29 maio 2006]; 2: [aprox. 7 telas]. Disponível em: http://www.claves.fiocruz.br/Boletim.PDF.

12. Bastos YGL, Andrade SM, Soares DA. Características dos acidentes de trânsito e das vitimas atendidas em serviço pré-hospitalar em cidade do sul do Brasil, 1997/2000. Cad Saude Publica 2005 maio/jun; 21 (3): 815-22.

13. Instituto de Pesquisa Econômica e Aplicada. IPEA. Impactos sociais e econômicos dos acidentes de trânsito nas aglomerações urbanas brasileiras. Relatório Executivo/IPEA/ANTP.Brasilia(DF): IPEA/ANTP; maio 2003. 